\title{
In-field evaluation of clinoptilolite feeding efficacy on the reduction of milk aflatoxin M1 concentration in dairy cattle
}

\author{
Panagiotis D. Katsoulos ${ }^{*}$, Maria A. Karatzia ${ }^{1}$, Constantinos Boscos ${ }^{1}$, Petra Wolf ${ }^{2}$ and Harilaos Karatzias ${ }^{1}$
}

\begin{abstract}
Background: Clinoptilolite is a natural zeolite with high adsorption capacity for polar mycotoxins such as aflatoxins. The efficacy of clinoptilolite in ameliorating the toxic effects of aflatoxicosis has been proven in monogastric animals, but there is no such evidence for ruminants. The aim of this study was to evaluate, under field conditions, whether the dietary administration of clinoptilolite in dairy cows could reduce the concentration of aflatoxin M1 $\left(\mathrm{AFM}_{1}\right.$ ) in bulk-tank milk, in farms with higher than or close to $0.05 \mathrm{\mu g} / \mathrm{kg}$ of milk (European maximum allowed residual level). An objective of the present study was also to investigate the effect of particle size of clinoptilolite on aflatoxin binding.

Methods: Fifteen commercial Greek dairy herds with AFM1 concentrations in bulk tank milk $\geq 0.05 \mu \mathrm{g} / \mathrm{kg}$ were selected. Bulk tank milk AFM1 was determined prior to the onset and on day 7 of the experiment. Clinoptilolite was added in the total mixed rations of all farms at the rate of $200 \mathrm{~g}$ per animal per day, throughout this period. Two different particle sizes of clinoptilolite were used; less than $0.15 \mathrm{~mm}$ in 9 farms (LC group) and less than $0.8 \mathrm{~mm}$ in 6 farms (HC group).
\end{abstract}

Results: Clinoptilolite administration significantly reduced AFM 1 concentrations in milk in all farms tested at an average rate of $56.2 \%$ (SD: 15.11). The mean milk AFM 1 concentration recorded on Day 7 was significantly $(P<0.001)$ lower compared to that of Day $0(0.036 \pm 0.0061$ vs. $0.078 \pm 0.0074 \mu \mathrm{g} / \mathrm{kg})$. In LC group farms the reduction of milk $\mathrm{AFM}_{1}$ concentration was significantly higher than $\mathrm{HC}$ group farms $(0.046 \pm 0.0074$ vs. $0.036 \pm$ $0.0061 \mu \mathrm{g} / \mathrm{kg}, P=0.002$ ). As indicated by the Pearson correlation, there was a significant and strong linear correlation among the milk AFM concentrations on Days 0 and $7(R=0.95, P<0.001)$.

Conclusions: Dietary administration of clinoptilolite, especially of smallest particle size, at the rate of $200 \mathrm{~g}$ per cow per day can effectively reduce milk $\mathrm{AFM}_{1}$ concentration in dairy cattle and can be used as a preventive measure for the amelioration of the risks associated with the presence of aflatoxins in the milk of dairy cows.

Key words: Aflatoxins, Clinoptilolite, Milk, Dairy cows

\footnotetext{
* Correspondence: katsoulo@vet.auth.gr

${ }^{1}$ Clinic of Farm Animals, School of Veterinary Sciences, Aristotle University of

Thessaloniki, 11 St. Voutyra str, Thessaloniki 54627, Greece

Full list of author information is available at the end of the article
} 


\section{Background}

Aflatoxins (AF) are hepatotoxic and carcinogenic secondary metabolic products from fungi belonging in particular to the Aspergillus flavus and A. parasiticus species [1, 2]. Aflatoxin B1 $\left(\mathrm{AFB}_{1}\right)$ is of major concern in dairy cattle. When fed to lactating animals, a part of this AF is destroyed in the rumen, whereas the absorbed quantity is rapidly oxidized mainly to aflatoxin M1 $\left(\mathrm{AFM}_{1}\right)$ [3-5]. Most of the $\mathrm{AFM}_{1}$ produced is excreted in the urine and less so in the milk $[6,7]$. The carry-over of $\mathrm{AFB}_{1}$ to $\mathrm{AFM}_{1}$ in milk depends on many factors such as milk yield and days in lactation [8-11] and ranges between $1 \%$ and $6 \%[11,12]$. As $\mathrm{AFM}_{1}$ is a possible human carcinogen [13], many countries have applied a maximum residue level for this aflatoxin in ruminant milk. For the EU this level is $0.05 \mu \mathrm{g} / \mathrm{kg}$ [12].

In dairy farms milk $\mathrm{AFM}_{1}$ concentration often either approaches or exceeds the aforementioned maximum residue level. In these cases it is common practice to add a mycotoxin binder in the ration until the detection and withdrawal of the contaminated feed. The role of these binders is to adsorb and reduce the intestinal absorption of mycotoxins to reduce the toxic effects for livestock and the carry-over of toxin compounds to animal products. Clinoptilolite is a natural zeolite, licensed by the EU as additive in feedstuffs of farm animals [14]. This material has high adsorption capacity for polar mycotoxins such as aflatoxins [15-17]. Concerning $\mathrm{AFB}_{1}$ specifically, it has been determined that $1 \mathrm{~g}$ of clinoptilolite can adsorb about $200 \mu \mathrm{g}$ of this aflatoxin [16]. The efficacy of clinoptilolite in ameliorating the toxic effects of aflatoxicosis has been proven in monogastric animals, especially in poultry [18-23]. Such trials scarce from the available literature for ruminants and there is no reference providing information about the potential use of clinoptilolite as aflatoxin binder in dairy cattle. However, the use of other alumonosilicate binders closely related to clinoptilolite such as hydrated sodium calcium aluminosilicate was proven to be effective in reducing $\mathrm{AFM}_{1}$ in milk of cattle [24] and goats [25] in experimentally induced aflatoxicosis.

Based on this evidence, the present study was designed in order to evaluate, under field conditions, whether the dietary administration of clinoptilolite in dairy cows could reduce the concentration of aflatoxin M1 (AFM $)_{1}$ in bulk-tank milk, in farms with higher than or close to $0.05 \mu \mathrm{g} / \mathrm{kg}$ of milk (European maximum allowed residual level). An objective of the present study was also to investigate the effect of particle size on the mycotoxins binding capacity of clinoptilolite.

\section{Methods}

The study was conducted in 15 commercial Greek herds with Holstein dairy cattle that had high concentrations of $\mathrm{AFM}_{1}$ in bulk tank milk (close to or higher than $0.05 \mu \mathrm{g} \mathrm{AFM}_{1} / \mathrm{kg}$ of milk), as detected at the routine analyses by the dairy industries collecting the milk. Milk $\mathrm{AFM}_{1}$ concentration was determined using their standard methods (ELISA) following the guidelines and recommendations described in ISO 14675/2003. The criteria for the selection of the farms were: a) the willingness of the farmers to use only clinoptilolite as mycotoxin binder without making any other changes to the rations offered to the animals during the experimental period b) the agreement of the milk industries to determine the $\mathrm{AFM}_{1}$ concentrations in the delivered bulk tank milk at fixed time-points and c) the difference between bulk tank milk $\mathrm{AFM}_{1}$ concentration at the initial measurement and at the onset of the experiment (3-10 days later) not being more than $10 \%$. In all these farms the total mixed rations offered to the animals were formulated by the attending animal scientists and met the requirements of the cows for maintenance and respective milk production. Herd size, average milk production per cow per day, average daily dry matter intake and farming system are presented in Table 1.

The study lasted for 7 days. On Day 0, the bulk tank milk $\mathrm{AFM}_{1}$ concentration was determined. For the next seven days (Days 1 to 7 ), clinoptilolite was added in the total mixed rations of all farms at the level of $200 \mathrm{~g}$ per animal per day. The rate of clinoptilolite supplementation (\% of the dry matter of the ration) is shown in Table 1 . The bulk tank milk $\mathrm{AFM}_{1}$ was also determined at the delivered milk produced on Day 7 of the experiment. The aflatoxin contaminated feedstuffs in the rations of 12 out of 15 farms, as stated by the farmers that analyzed their feedstuffs in private laboratories on their own initiative are presented in Table 1.

\section{Clinoptilolite}

The clinoptilolite-rich zeolitic material (Vivolith 85, $\mathrm{S} \& \mathrm{~B}$, Greece) used in all farms contained at least $85 \%(85 \%-87 \%)$ clinoptilolite according to the analyses provided by the manufacturer for the batches used; the admixtures were feldspar, micas and clays as determined by $x$-ray powder diffraction. The cation exchange capacity of the material used was $160 \mathrm{mEq} /$ $100 \mathrm{~g}$ and its chemical composition was as follows: $\mathrm{SiO}_{2} 68.3 \%, \mathrm{Al}_{2} \mathrm{O}_{3} 12.8 \%, \mathrm{Fe}_{2} \mathrm{O}_{3} 1.1 \%, \mathrm{CaO} 3.2 \%$, $\mathrm{MgO} 0.7 \%, \mathrm{~K}_{2} \mathrm{O} 3.4 \%, \mathrm{Na}_{2} \mathrm{O} 1.0 \%$ and loss on ignition (LOI) $8.5 \%$.

According to the size of zeolite, farms were allocated into two groups. The first group (SC) consisted of 9 farms that used a particle size of less than $0.15 \mathrm{~mm}$ and the second group (LC) of the other 6 farms that used a particle size of less than $0.8 \mathrm{~mm}$ (Table 1). The allocation to these groups was completely randomized. 
Table 1 Herd size, farming system (Free stall: FS; Cubicle with earthen paddocks: CEP), average daily milk yield per cow, dry matter intake (DMI), contaminated feeds in the ration, inclusion rate of clinoptilolite (\% dry matter; \% DM) and grouping according to the particle size of clinoptilolite (SC: $<0.15 \mathrm{~mm}, \mathrm{LC}:<0.8 \mathrm{~mm}$ ) in the 15 farms (F1 to F15) included in the study

\begin{tabular}{|c|c|c|c|c|c|c|c|}
\hline Group & Farm I.D. & Herd Size & Farming system & $\begin{array}{l}\text { Average daily } \\
\text { milk yield (kg) }\end{array}$ & DMI (kg) & $\begin{array}{l}\text { Clinoptilolite inclusion } \\
\text { rate (\% DM) }\end{array}$ & Contaminated feed $^{a}$ \\
\hline SC & F1 & 220 & CEP & 32 & 20.6 & 0.97 & Corn silage \\
\hline SC & F2 & 246 & CEP & 30 & 20 & 1.00 & Corn silage \\
\hline SC & F5 & 125 & CEP & 30 & 20 & 1.00 & $\mathrm{DDGS}^{\mathrm{b}}$ \\
\hline SC & F6 & 172 & FS & 33 & 20.5 & 0.98 & Maize grains \& cottonseed meal \\
\hline SC & F8 & 50 & FS & 25 & 18.8 & 1.06 & Maize grains \\
\hline SC & F9 & 87 & FS & 27 & 19.2 & 1.04 & Maize grains \\
\hline SC & F10 & 120 & CEP & 31 & 20.2 & 0.99 & Maize grains \\
\hline SC & F11 & 136 & CEP & 36 & 22.0 & 0.91 & Maize grains \\
\hline SC & F13 & 175 & FS & 29 & 19.9 & 1.01 & $N / D^{c}$ \\
\hline LC & F3 & 180 & FS & 28 & 19.5 & 1.03 & $\mathrm{DDGS}^{\mathrm{b}}$ \\
\hline LC & F4 & 146 & FS & 33 & 20.8 & 0.96 & Corn silage \\
\hline LC & F7 & 163 & CEP & 29 & 19.7 & 1.02 & Maize grains \\
\hline LC & F12 & 90 & FS & 35 & 21.8 & 0.92 & Maize grains \\
\hline LC & F14 & 74 & FS & 26 & 18.7 & 1.07 & $N / D^{c}$ \\
\hline LC & F15 & 150 & FS & 33 & 20.2 & 0.99 & $N / D^{c}$ \\
\hline
\end{tabular}

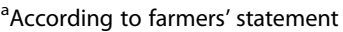

${ }^{b}$ Distiller's dried grains with solubles

${ }^{\mathrm{c}}$ Not determined

\section{Ethics}

The procedures and the experiment were done according to the ethical standards in the Helsinki Declaration of 1975 , as revised in 2000 , as well as the national law and the guidelines of our Institutional Animal Care and Use Committee.

\section{Statistical analysis}

Data were analyzed using the statistical program SPSS ${ }^{\oplus}$ 21. Normality of data distribution was assessed with Kolmogorov-Smirnov test and homogeneity of variances was evaluated with Levene's test. Repeated measures analysis was run to evaluate the significance of the differences among the AFM1 concentrations in the bulk tank milk before (Day 0) and after the administration of clinoptilolite (Day 7). Univariate analysis of variance was also used for the comparison of the absolute differences (AD) and the absolute relative differences (ARD) of the $\mathrm{AFM}_{1}$ concentration in milk at the onset and the end of the study period between the two groups (SC and LC) of farms $\quad\left(\mathrm{AD}=\mathrm{AFM}_{10^{-}} \quad \mathrm{AFM}_{1 \mathrm{~F}}\right.$ and $\mathrm{ARD}=100 \mathrm{xAD} /$ $\mathrm{AFM}_{1}$; where $\mathrm{AFM}_{1 \mathrm{~F}}$ represents the milk $\mathrm{AFM}_{1}$ concentration on Day 7 and $\mathrm{AFM}_{1}$ the milk $\mathrm{AFM}_{1}$ concentration on Day 0). Bonferroni test was used as an adjustment factor for the comparison of the main effects of time and group respectively in the former models. The linear association between the milk $\mathrm{AFM}_{1}$ concentrations on Days 0 and 7 was assessed by the use of the
Pearson Correlation Coefficient test and Linear Regression Analysis was used to determine the equations predicting the milk $\mathrm{AFM}_{1}$ concentration after clinoptilolite administration. A value of $p \leq 0.05$ was considered significant in all comparisons. The sensitivity and the specificity for the correct prediction of individual farms with or without milk $\mathrm{AFM}_{1}$ concentration over $0.05 \mu \mathrm{g} / \mathrm{kg}$ after clinoptilolite administration using the generated equation was calculated using MedCalc Diagnostic test evaluation calculator (available at: https://www.medcalc.org/calc/diagnostic_test.php).

\section{Results}

The inclusion rate of clinoptilolite in the total mixed rations of the 15 farms included in the study is presented in Table 1 . On average, the inclusion rate was $1 \%$ (SD: $0.05)$ of the ration's dry matter (DM).

As it is shown in Fig. 1, reduced milk $\mathrm{AFM}_{1}$ concentrations were recorded in all farms tested after the dietary inclusion of clinoptilolite (Day 7) compared to Day 0. On average, milk $\mathrm{AFM}_{1}$ concentration on Day 7 was significantly lower compared to Day 0 (mean \pm SE: $0.078 \pm 0.0074 \mu \mathrm{g} / \mathrm{kg}$ and $0.036 \pm 0.0061 \mu \mathrm{g} / \mathrm{kg}$ for Days 0 and 7 , respectively, $P<0.001)$. Moreover, the average AD was $0.04 \mu \mathrm{g} / \mathrm{kg}$ (SD: 0.01) and the average ARD was $56.2 \%$ (SD: 15.11). In farms of the LC group the average AD of milk $\mathrm{AFM}_{1}$ concentration was significantly higher than that in farms of $\mathrm{HC}$ group (mean $\pm \mathrm{SE}: 0.046 \pm 0.0074 \mu \mathrm{g} / \mathrm{kg}$ 


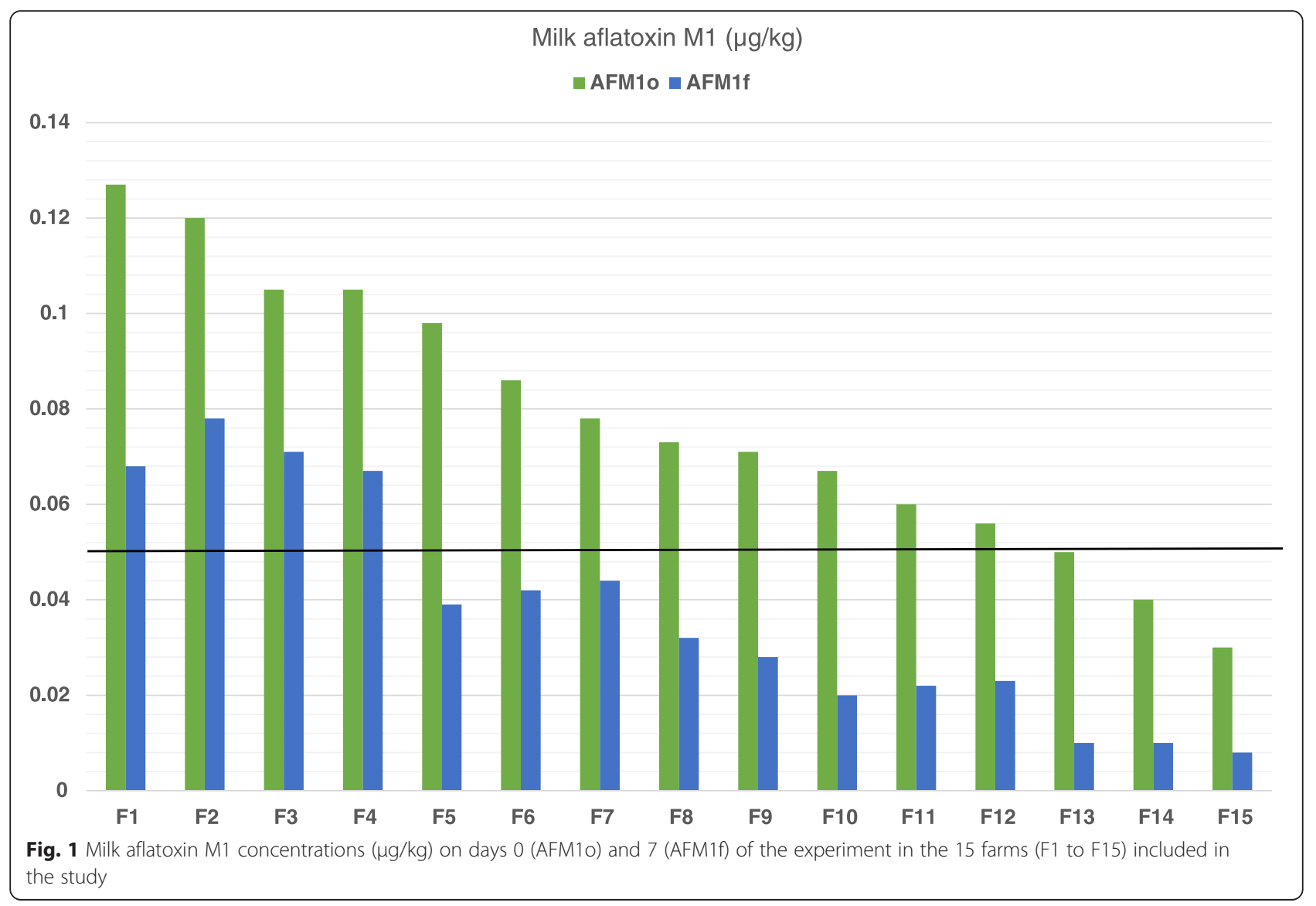

and $0.036 \pm 0.0061 \mu \mathrm{g} / \mathrm{kg}$ for groups $\mathrm{LC}$ and $\mathrm{HC}$, respectively, $P=0.002$; Fig. 2). However, the average ARD was not significantly different among groups (mean \pm SE: $58.1 \pm$ $13.15 \%$ and $53.2 \pm 18.6 \%$ for groups LC and HC, respectively, $P=0.56$ ).

As indicated by the Pearson correlation, there was a significant and strong linear correlation among the milk $\mathrm{AFM}_{1}$ concentrations on Days 0 and $7(\mathrm{R}=0.95$, $P<0.001)$. According to the results of regression analysis, the equation yielding the predicting value of milk $\mathrm{AFM}_{1}$ concentration after the administration of clinoptilolite (Day 7) was:

$$
\begin{aligned}
\mathrm{AFM}_{1 \mathrm{~F}}= & 0.781 \\
& \times \mathrm{AFM}_{10}-0.023,\left(\mathrm{r}^{2}=0.899, \mathrm{P}<0.001\right),
\end{aligned}
$$

where $\mathrm{AFM}_{1 \mathrm{~F}}$ represents the milk $\mathrm{AFM}_{1}$ concentration on Day 7 and $\mathrm{AFM}_{10}$ the milk $\mathrm{AFM}_{1}$ concentration on Day 0 (Fig. 3).

The sensitivity of the correct prediction of individual farms with or without milk $\mathrm{AFM}_{1}$ concentration over $0.05 \mu \mathrm{g} \mathrm{AFM} / \mathrm{kg}$ after clinoptilolite administration using this equation was $100 \%$ and the specificity was $90.91 \%$.

\section{Discussion}

The objective of the present study was to evaluate the efficacy of a natural zeolite; clinoptilolite, as aflatoxin binder in dairy cattle. It was selected to run the study in natural cases rather than experimentally induced aflatoxicoses which is the common practice in most of the studies [9, $26,27]$ evaluating other mycotoxin binders. It was done not only for welfare reasons but also because such a study design would allow us to test the efficacy of clinoptilolite under field conditions and to have a considerable number of replications by using different farms. Besides, the in vitro and the in vivo studies that preceded in other animal species [15-23] provided enough evidence for potential efficiency of the binder on the reduction of aflatoxins. The criteria of farm selection were set in order to ensure, as most as possible, that the milk $\mathrm{AFM}_{1}$ concentration on day 0 represents a stable situation of high milk $\mathrm{AFM}_{1}$ and that the reductions detected on day 7 are due to the infeed inclusion of clinoptilolite. The dosage rate of clinoptilolite offered daily to the animals was chosen to be $200 \mathrm{~g}$ per animal per day because this amount is safe for longterm consumption and has beneficial effects on the health status and the performance of dairy cows [28]. Furthermore, this daily dose represented the $1 \%$ of ration DM, 


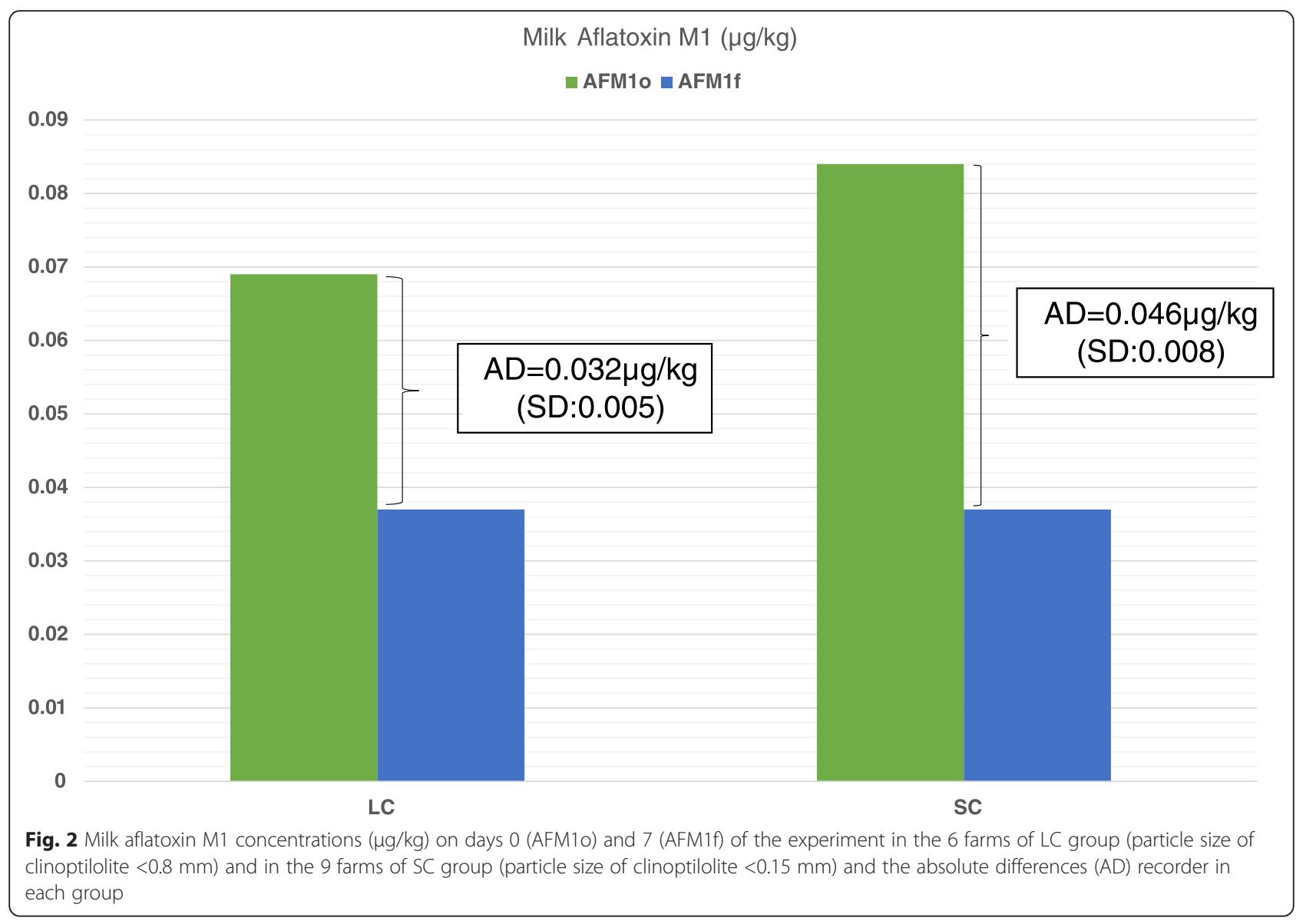

on average, which is within the rates most commonly used for the evaluation of a mycotoxin adsorbent in dairy cows $[9,26,27]$. According to our observations during a series of experiments [28], the addition of clinoptilolite at this level in the total mixed rations has no effect on the feed consumption even from the first day of administration. So, no gradual increase of the amount of clinoptilolite fed was judged to be necessary prior to the onset of the evaluation period and the selected daily dose was offered to the animals from the first day of the study. The duration of 7 days was considered to be adequate as study period given that it is about double the clearance time after the removal of aflatoxins of the dairy cattle diet which is about 3-4 days [9, 10, 27].

The results obtained here prove that the dietary administration of clinoptilolite is effective in reducing the milk concentration of $\mathrm{AFM}_{1}$, given the practically stable $\mathrm{AFM}_{1}$ milk concentration from the first detection by the milk industries until the onset of the experiment and the continuous use of the same rations without any change until the end of the experiment. With the exception of the 4 farms where the initial milk $\mathrm{AFM}_{1}$ concentration was higher than $0.1 \mu \mathrm{g} / \mathrm{kg}$, in all other cases the final $\mathrm{AFM}_{1}$ concentration was below the maximum residue level of $0.05 \mu \mathrm{g} / \mathrm{kg}$. This indicates that the dosage rate of $200 \mathrm{~g}$ clinoptilolite per cow per day, is adequate for the prevention of aflatoxicosis with $\mathrm{AFM}_{1}$ milk concentrations lower than $0.1 \mu \mathrm{g} / \mathrm{kg}$. The average relative reduction of milk $\mathrm{AFM}_{1}$ recorded at this study, although not comparable with other experiments due to different study design, was similar to those achieved with other aluminocilicate mycotoxin binders; Diaz et al. [9] observed that calcium and sodium bentonite products reduce milk $\mathrm{AFM}_{1}$ concentrations by $31 \%$ to $65 \%$ and Kutz et al. [25] that two hydrated sodium calcium aluminocilicates decrease the $\mathrm{AFM}_{1}$ by 45 and $48 \%$. The relatively high standard deviation, about $25 \%$ of the means, of the AD and the ARD recorded is probably due to the wide range of initial milk $\mathrm{AFM}_{1}$ concentrations, to the large variation of the carry-over rate of AFB1 to AFM1 in milk [8-11] and to the differences of the rations offered to the animals among farms.

The use of clinoptilolite-rich material with the particle size of less than $0.15 \mathrm{~mm}$ resulted in significantly higher decrease of milk $\mathrm{AFM}_{1}$ concentration than the one of less than $0.8 \mathrm{~mm}$. Due to the porous nature of clinoptilolite, the smaller particle size provides a larger surface that is available for interaction with the polar mycotoxins such as 


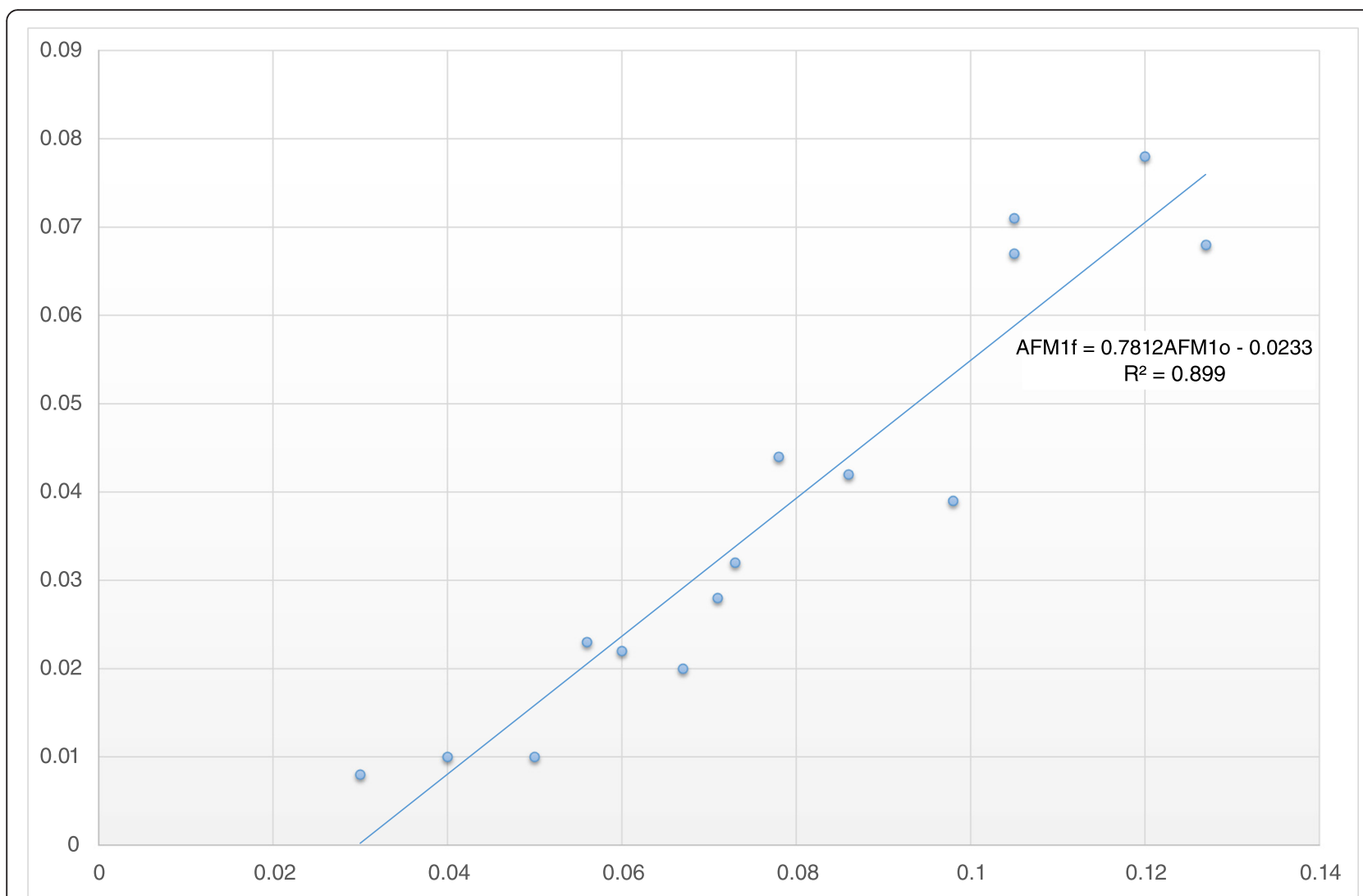

Fig. 3 Scatterplot with linear regression equation of the milk aflatoxin M1 concentration on days 0 (AFM10) and 7 (AFM1f) of the experiment

aflatoxins [29]. So, the $<0.15 \mathrm{~mm}$ clinoptilolite adsorbed higher quantities of $\mathrm{AFB}_{1}$ in the gastrointestinal tract than the $<0.8 \mathrm{~mm}$ one. The absence of significant difference on the average absolute relative reduction between groups is associated with the higher average milk $\mathrm{AFM}_{1}$ concentrations recorded on the LC group compared to $\mathrm{HC}$.

Another interesting finding was the strong linear relationship among the initial and the final $\mathrm{AFM}_{1}$ milk concentration and the high value of the coefficient of determination of the regression equation produced. The very high sensitivity and specificity values determined denote that using this equation it is possible to predict whether the milk AFM1 concentration will be lower than the maximum residue level of $0.05 \mu \mathrm{g} / \mathrm{kg}$ or not. If not, the simultaneous use of another aflatoxin binder or the administration of higher amounts of clinoptilolite should be considered given that the adsorption of aflatoxins by aluminosilicate binders occurs in a dose dependent manner [30]. Besides, higher daily doses of clinoptilolite than $200 \mathrm{~g}$ in dairy cattle are safe even for long-term administration [28].

\section{Conclusions}

In the context of this study it can be concluded that the dietary administration of clinoptilolite, especially of smallest particle size, can effectively reduce milk $\mathrm{AFM}_{1}$ concentration in dairy cattle. Taking into consideration the relatively low commercial price of clinoptilolite (0.30-0.40 Euros per $\mathrm{kg}$ ) and that the long-term dietary supplementation of clinoptilolite is safe and has beneficial effects on the health status and productivity of dairy cattle, without adding any extra labour in the farm's routine, clinoptilolite feeding at the rate of $200 \mathrm{~g}$ per cow per day can be used as a preventive measure for the amelioration of the risks associated with the presence of aflatoxins in the milk of dairy cows. Of course, further research using higher inclusion rates of clinoptilolite is regarded necessary in order to evaluate its efficacy when bulk tank milk $\mathrm{AFM}_{1}$ levels are higher than $0.1 \mu \mathrm{g} / \mathrm{kg}$.

\section{Abbreviations}

AFM1, aflatoxin M1; AFB1, aflatoxin B1; LC, clinoptilolite with $<0.15 \mathrm{~mm}$ particle size; $\mathrm{HC}$, clinoptilolite with $<0.8$ $\mathrm{mm}$ particle size; SD, standard deviation; SE, standard error; AFM1F, milk aflatoxin M1concentration on Day 7; AFM1o, milk aflatoxin M1 concentration on Day 0; AD, absolute differences; ARD, absolute relative differences; DM, dry matter; DMI, dry matter intake; FS, free stall; CEP, Cubicle with earthen paddocks. 


\section{Authors' contributions}

PDK and MAK contributed in conceiving the idea, designing of the experiment, collecting the data, statistical processing and drafting the manuscript. CB and PW contributed in designing the study, interpreting the results and revising the manuscript. HK designed and supervised the study and critically revised the manuscript. All authors read and approved the final manuscript.

\section{Competing interests}

The authors declare that they have no competing interests.

\section{Author details}

${ }^{1}$ Clinic of Farm Animals, School of Veterinary Sciences, Aristotle University of Thessaloniki, 11 St. Voutyra str, Thessaloniki 54627, Greece. ${ }^{2}$ Institute for Nutrition Physiology and Animal Nutrition, University of Rostock, Justus-von-Liebig-Weg 6b, Rostock 18059, Germany.

\section{Received: 12 February 2016 Accepted: 17 May 2016}

\section{Published online: 22 June 2016}

\section{References}

1. Creppy EE. Update of survey, regulation and toxic effects of mycotoxins in Europe. Toxicol Lett. 2002;127:19-28.

2. Binder EM, Tan LM, Chin LJ, Handl J, Richard J. Worldwide occurrence of mycotoxins in commodities, feeds and feed ingredients. Anim Feed Sci Technol. 2007:137:265-82.

3. Kuilman MEM, Maas RFM, Judah DJ, Fink-Gremmels J. Bovine hepatic metabolism of aflatoxin B1. J Agric Food Chem. 1998;46:2707-13.

4. Kuilman MEM, Maas RFM, Fink-Gremmels J. Cytochrome P450-mediated metabolism and cytotoxicity of aflatoxin B1 in bovine hepatocytes. Toxicol In Vitro. 2000:14:321-7.

5. Kensler TW, Roebuck BD, Wogan GN, Groopman JD. Aflatoxin: A 50-year odyssey of mechanistic and translational toxicology. Toxicol Sci. 2011;120:528-48

6. van Egmond HP. Aflatoxin M1: Occurrence, Toxicity, Regulation. In: van Egmond HP, editor. Mycotoxins in Dairy Products. London: Elsevier Applied Science: 1989. p. 11-55.

7. Prandini A, Tansini G, Sigolo S, Filippi L, Laporta M, Piva G. On the occurrence of aflatoxin M1 in milk and dairy products. Food Chem Toxicol. 2007:47:984-91.

8. Veldman A, Meijs JAC, Borggreve J,Heeres-van der Tol JJ. Carry-over of aflatoxin from cows' food to milk. Anim Prod. 199;255:163-8.

9. Diaz DE, Hagler JWM, Blackwelder JT, Eve JA, Hopkins BA, Anderson KL, Jones FT, Whitlow LW. Aflatoxin binders II: Reduction of aflatoxin M1 in milk by sequestering agents of cows consuming aflatoxin in feed. Mycopathologia. 2004;157:233-41

10. Masoero F, Gallo A, Moschini M, Piva G, Diaz D. Carry-over of aflatoxin from feed to milk in dairy cows with low or high somatic cell counts. Animal. 2007:1:1344-50

11. Britzi M, Friedman S, Miron J, Solomon R, Cuneah O, Shimshoni JA, Soback S, Ashkenazi R, Armer S, Shlosberg A. Carry-over of aflatoxin B1 to aflatoxin M1 in high yielding Israeli cows in mid- and late-lactation. Toxins. 2013;5: 173-83.

12. European Food Safety Authority (EFSA). Opinion of the scientific panel on contaminants in the food chain on a request from the Commission related to aflatoxin B1 as undesirable substance in animal feed. EFSA J. 2004:39:127.

13. International Agency for Research on Cancer (IARC). Aflatoxins. IARC Monographs on the Evaluation of Carcinogenic Risks to Humans, vol. 62. Lyon: IARC Press; 2002.

14. European Commission Implementing Regulation (EU) 651/2013 of 9 July 2013 concerning the authorisation of clinoptilolite of sedimentary origin as a feed additive for all animal species and amending Regulation (EC) No 1810/2005. Off J Eur Union. 10/7/2013;L 189:1-3.

15. Dacovic A, Tomacevic-Canovic M, Dondur V, Vujakovic A, Radosevic P. Kinetics of aflatoxin B1 and G2 adsorption on Ca-clinoptilolite. J Serb Chem Soc. 2000;65:715-23.

16. Tomacevic-Canovic M, Dacovic A, Markovic V, Stojcic D. The effect of exchangeable cations in clinoptilolite and montmorillonite on the adsorption of aflatoxin B1. J Serb Chem Soc. 2001;66:555-61.
17. Spotti M, Fracchiolla ML, Arioli F, Caloni F, Pompa G. Aflatoxin B1 binding to sorbents in bovine ruminal fluid. Vet Res Commun. 2005:29:507-15.

18. Schell TC, Lindemann MD, Kornegay ET, Blodgett DJ, Doer JA. Effectiveness of different types of clay for reducing the detrimental effects of aflatoxincontaminated diets on performance and serum profiles of weanling pigs. J Anim Sci. 1993;71:1226-31.

19. Oguz H, Kececi T, Birdane YO, Onder F, Kurtoglu V. Effect of clinoptilolite on serum biochemical and haematological characters of broiler chickens during experimental aflatoxicosis. Res Vet Sci. 2000;69:89-93.

20. Oguz H, Kurtoglu V, Coskun B. Preventive efficacy of clinoptilolite in broilers during chronic aflatoxin (50 and 100 ppb) exposure. Res Vet Sci. 2000;69: 197-201.

21. Ortatatli $\mathrm{M}, \mathrm{Oguz} \mathrm{H}$. Ameliorative effects of dietary clinoptilolite on pathological changes in broiler chickens during aflatoxicosis. Res Vet Sci. 2001;71:59-66.

22. Safameher A. Effects of Clinoptilolite on Performance, Biochemical Parameters and Hepatic Lesions in Broiler Chickens during Aflatoxosis. J Anim Vet Adv. 2008:7:381-8.

23. Maslic-Strizak D, Spalevic L, Resanovic R. Testing the possibility of zeolite application on poultry exposed to the G2 aflatoxin effect. Maced J Anim Sci. 2013;3:181-8

24. Harvey RB, Phillips TD, Ellis JA, Kubena LF, Huff WE, Petersen HD. Effects on aflatoxin $\mathrm{M} 1$ residues in milk by addition of hydrated sodium calcium aluminosilicate to aflatoxin-contaminated diets of dairy cows. Am J Vet Res. 1991;52:1556-9.

25. Smith EE, Phillips TD, Ellis JA, Harvey RB, Kubena LF, Thompson J, Newton G. Dietary hydrated sodium calcium aluminosilicate reduction of aflatoxin M1 residue in dairy goat milk and effects on milk production and components. Anim Sci. 1994;72:677-82

26. Kutz RE, Sampson JD, Pompeu LB, Ledoux DR, Spain JN, Vázquez-Añón M, Rottinghaus GE. Efficacy of Solis, NovasilPlus, and MTB-100 to reduce aflatoxin M1 levels in milk of early to mid lactation dairy cows fed aflatoxin B1. J Dairy Sci. 2009:92:3959-63.

27. Queiroz OCM, Han JH, Staples CR, Adesogan AT. Effect of adding a mycotoxin-sequestering agent on milk aflatoxin M1 concentration and the performance and immune response of dairy cattle fed an aflatoxin B1contaminated diet. J Dairy Sci. 2012:95:5901-8.

28. Katsoulos PD, Karatzia MA, Karatzias H. The Use of Clinoptilolite as Feed Additive for the Prevention and Treatment of Certain Diseases in Cattle. In: Lieu G, editor. Cattle: Domestication, Diseases and the Environment. New York: Nova Science Publishers Inc; 2013. p. 115-26.

29. Papaioannou D, Katsoulos PD, Panousis N, Karatzias $H$. The role of natural and synthetic zeolites as feed additives on the prevention and/or the treatment of certain farm animal diseases: a review. Micropor Mesopor Mat. $2005 ; 84: 161-70$

30. Sarr AB. Effects of phyllosilicate clay on the metabolic profile of aflatoxin B1 in Fischer-344 rats. Toxicol Lett. 1995;75:145-51.

\section{Submit your next manuscript to BioMed Central and we will help you at every step:}

- We accept pre-submission inquiries

- Our selector tool helps you to find the most relevant journal

- We provide round the clock customer support

- Convenient online submission

- Thorough peer review

- Inclusion in PubMed and all major indexing services

- Maximum visibility for your research

Submit your manuscript at www.biomedcentral.com/submit 